\title{
BMJ Open Factors associated with non-initiation of mental healthcare after detection of poor mental health at a scheduled health check: a cohort study
}

\author{
Christine Geyti (D) , ${ }^{1}$ Kaj Sparle Christensen (D) , ${ }^{1,2}$ Else-Marie Dalsgaard (D) , \\ Bodil Hammer Bech (D) , 'Jane Gunn (D) , ${ }^{3}$ Helle Terkildsen Maindal (D) , ${ }^{1}$ \\ Annelli Sandbaek (iD) ${ }^{1,4}$
}

To cite: Geyti C, Christensen KS, Dalsgaard E-M, et al. Factors associated with non-initiation of mental healthcare after detection of poor mental health at a scheduled health check: a cohort study. BMJ Open 2020;10:e037731. doi:10.1136/ bmjopen-2020-037731

- Prepublication history and additional material for this paper are available online. To view these files, please visit the journal online (http://dx.doi org/10.1136/bmjopen-2020037731).

Received 13 February 2020 Revised 13 September 2020 Accepted 15 September 2020

A) Check for updates

C Author(s) (or their employer(s)) 2020. Re-use permitted under CC BY-NC. No commercial re-use. See rights and permissions. Published by BMJ.

${ }^{1}$ Department of Public Health, Aarhus University, Aarhus, Denmark

${ }^{2}$ Research Unit for General Practice, Aarhus, Denmark ${ }^{3}$ Department of General Practice, The University of Melbourne, Melbourne, Victoria, Australia ${ }^{4}$ Steno Diabetes Center Aarhus, Aarhus University Hospital, Aarhus, Denmark

Correspondence to

Christine Geyti;

christine.geyti@ph.au.dk

\section{ABSTRACT}

Introduction Poor mental health is an important public health concern, but mental health problems are often under-recognised. Providing feedback to general practitioners (GPs) on their patients' mental health status may improve the identification of cases in need of mental healthcare.

Objectives To investigate the extent of initiation of mental healthcare after identification of poor mental health and to identify factors associated with non-initiation.

Design Prospective cohort study with 1-year follow-up.

Setting In a population-based health preventive programme, Check Your Health, we conducted a combined mental and physical health check in Randers Municipality, Denmark, in 2012-2015 in collaboration with local GPs. Participants Participants were 350 individuals aged 3049 years old with screen-detected poor mental health who had not received mental healthcare within the past year. The cohort was derived from 14167 randomly selected individuals of whom $52 \%(n=7348)$ participated. Mental health was assessed by the mental component summary score of the 12-item Short-Form Health Survey. Outcome The outcome was initiation of mental healthcare. Mental healthcare included psychometric testing by GP, talk therapy by GP, contact with a psychologist, contact with a psychiatrist and psychotropic medication.

Results Within 1 year, $22 \%$ (95\% Cl 18 to 27) of individuals with screen-detected poor mental health initiated mental healthcare. Among individuals who initiated mental healthcare within follow-up, one in six had visited their GP once or less in the preceding year. Male sex (OR: 0.49 (95\% Cl 0.28 to 0.86)) and less impaired mental health (OR: 0.93 (95\% Cl 0.89 to 0.98)) were associated with non-initiation of mental healthcare. We found no overall association between socioeconomic factors and initiating mental healthcare.

Conclusion Systematic provision of mental health test results to GPs may improve the identification of cases in need of mental healthcare, but does not translate into initiation of mental healthcare. Further research should focus on methods to improve initiation of mental healthcare, especially among men.

Trial registration number NCT02028195.
Strengths and limitations of this study

- This is the first study to investigate the factors associated with non-initiation of mental healthcare after screen-detected poor mental health in a populationbased health check with feedback of results to the general practitioner.

- The study was based on a large-scale intervention programme implemented in the existing healthcare system.

- The use of national registers ensured complete follow-up data.

- However, national registers do not contain information on all types of mental healthcare.

- Although a valid mental health measure was used, it does not ensure that those detected with poor mental health are truly in need of mental healthcare.

\section{INTRODUCTION}

Poor mental health is an important public health concern. More than one-third of adult Europeans are estimated to experience mental ill health every year, ${ }^{1}$ and comorbidity is often seen between mental and chronic physical disorders. ${ }^{23}$ Poor mental health is a leading cause of disease burden, resulting in large economic costs and socioeconomic inequalities. $^{4-6}$

In Denmark, the majority of mental health problems are managed by general practitioners $(\mathrm{GPs}),{ }^{7}$ as they are in other European countries. For example, 96\% of British patients in treatment for a depressive disorder are treated by GPs. ${ }^{8}$ GPs also act as gatekeepers to secondary mental healthcare. Danish GPs are in contact with approximately $85 \%$ of their listed population at least once per year. ${ }^{9}$ Thus, general practice is a key place to focus when aiming to improve mental healthcare. However, mental health problems are often under-recognised in primary 
care. A meta-analysis suggested that only $50 \%$ of patients with depression were correctly identified by GPs. ${ }^{10}$ This could be due to the limited time and resources of the GPs. Moreover, mental distress often presents as physical complaints. ${ }^{11}$

The effectiveness of screening for mental disorders in the primary care setting has been the subject of debate, with studies reporting mixed results. ${ }^{12-14}$ However, giving feedback on the screening result to the GPs may assist in identifying cases in need of mental healthcare..$^{15} 16$ This could be especially important for individuals who are not regular visitors to their GPs. ${ }^{16}$

To motivate individuals to accept offers of mental healthcare once identified can be a challenge. ${ }^{17}$ Few studies have focused on initiation of mental healthcare among individuals screened positive, ${ }^{18-20}$ and only one of the identified studies provided feedback on the test result to the individual and to the GP. ${ }^{20}$

A concern in health screening initiatives is whether those with more resources will benefit the most from the initiative, whereas persons with more disadvantaged socioeconomic characteristics will benefit less. However, to our knowledge, no studies have identified factors of importance for initiation of mental healthcare after screen-detected mental health problems.

We conducted a combined mental and physical health check and provided feedback on the results to the individual and to the individual's GP to explore the extent of initiation of mental healthcare in individuals with screendetected poor mental health who received no mental healthcare in the year preceding the health check. Further, this study aimed to investigate the factors associated with non-initiation of mental healthcare.

From the literature on factors associated with mental healthcare, we selected explanatory variables that could have influenced the individual's likelihood of initiation of mental healthcare after the health check: severity of the mental health condition ${ }^{21} 22$ and sociodemographic factors. ${ }^{2123-25}$

As initiation of mental healthcare after a combined mental and physical health check has not previously been investigated, we wanted to explore if the presence of red flags (table 1) at the health check would influence initiation of mental healthcare. We hypothesised that red flags at the health check would increase the probability that the individual would book an appointment with the GP, and hence increase the probability of initiation of mental healthcare.

\section{METHODS}

\section{Setting}

The Check Your Health preventive programme was a largescale, population-based preventive health programme in Randers, a mid-sized municipality in Denmark. The programme included a combined mental and physical health check offered to all citizens aged 30-49 years in Randers Municipality, except individuals listed with a
Table 1 Red flags: health check test results prompting a recommendation for a follow-up consultation with the GP, Check Your Health

\begin{tabular}{|c|c|}
\hline Health check result & Details \\
\hline Poor mental health & MCS score $\leq 35.76$ \\
\hline $\begin{array}{l}\text { High CVD/DM risk } \\
\text { profile }\end{array}$ & $\begin{array}{l}\text { Systolic } \mathrm{BP} \geq 140 \text {, diastolic } \mathrm{BP} \geq 95 \text {, } \\
\mathrm{HbA} 1 \mathrm{c} \geq 6.0 \% \text {, total cholesterol } \geq 6 \\
\mathrm{mmol} / \mathrm{L}, \mathrm{LDL} \geq 6 \mathrm{mmol} / \mathrm{L} \text { or risk of } \\
\text { CVD within } 10 \text { years } \geq 5 \% \text {. }\end{array}$ \\
\hline Reduced lung function & $\begin{array}{l}\mathrm{FEV}_{1} \text { or } \mathrm{FVC} \leq 80 \% \text { or } \mathrm{FEV}_{1} / \mathrm{FVC} \\
\leq 0.70\end{array}$ \\
\hline Alcohol risk behaviour & $\begin{array}{l}\text { CAGE-C } \geq 2 \text { positive answers to } \\
\text { items } 1-4 \text { and } 6 \text {, or one positive } \\
\text { answer to items } 1-4 \text { and } 6 \text {, plus } \\
\text { alcohol intake on } \geq 4 \text { days per week, } \\
\text { AUDIT score } \geq 8 \text { or } \geq 21 \text { alcohol units } \\
\text { per week (men) or AUDIT score } \\
\geq 8 \text { or } \geq 14 \text { alcohol units per week } \\
\text { (women). }\end{array}$ \\
\hline $\begin{array}{l}\text { Poor/fair self rated } \\
\text { health }\end{array}$ & SF-12 item 1. \\
\hline
\end{tabular}

AUDIT, Alcohol Use Disorders Identification Test; BP, blood pressure; CAGE-C, Cut down, Annoyed, Guilty, Eye-opener (Copenhagen); CVD, cardiovascular disease; DM, diabetes mellitus; $F_{E V}$, forced expiratory volume in $1 \mathrm{~s}$; FVC, forced vital capacity; GP, general practitioner; HbA1c, glycated haemoglobin; LDL, low-density lipoprotein; MCS, mental component summary (from SF-12, V.2, US norms of 1998); SF-12, 12-item Short-Form Health Survey.

GP outside of Randers Municipality, individuals with terminal illness (as reported by the GP) and individuals who had emigrated from the municipality before the planned date of invitation. The programme targeted this age group because of the potential to prevent development of mental and physical conditions and related complications. ${ }^{26}$

The Check Your Health preventive programme was conducted as a randomised trial to investigate the effects of preventive health checks. Full details of the randomised controlled trial are published elsewhere. ${ }^{27}$ Briefly, the programme was developed in a collaboration between the local GPs in Randers Municipality, the health centre in the Municipality, the Central Denmark Region and Aarhus University. ${ }^{27}$ Citizens in the $30-49$ years age group who lived in Randers Municipality on 1 January 2012 were identified in the Danish Civil Register $(\mathrm{n}=26216)$.

The health check was performed at the local community health centre and consisted of a mental health screening test and a risk assessment of developing noncommunicable diseases, such as cardiovascular disease. This assessment was based on survey data and a clinical examination. Immediately after the health check examination, the individual received a personal health profile pamphlet and took part in a discussion of the results, with the health professional going through the results with the individual. Individuals assessed to have poor mental 


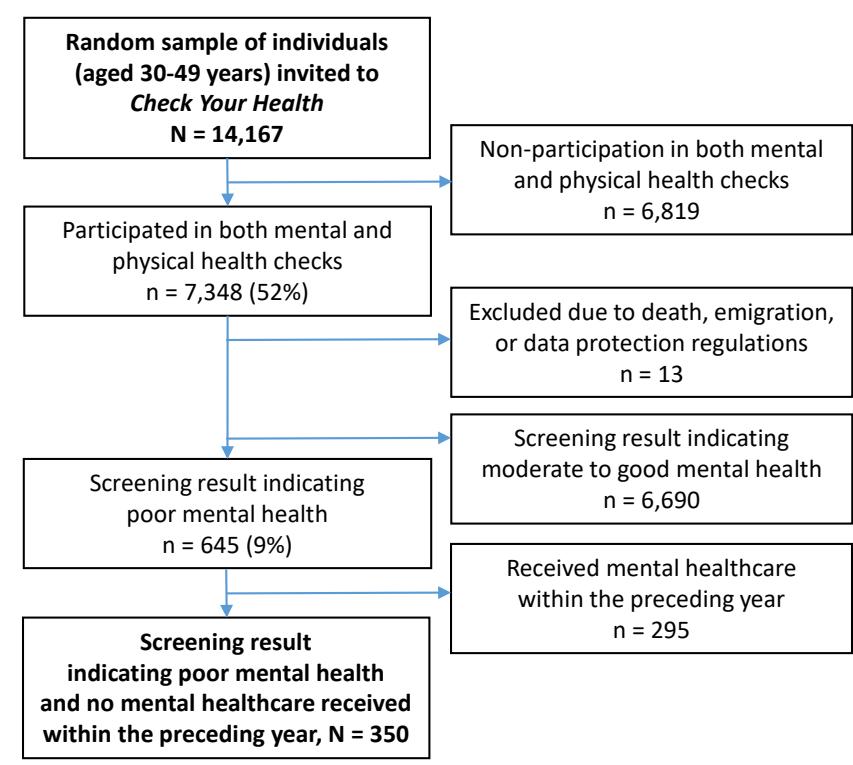

Figure 1 Flow chart of study population. Check Your Health: a health preventive programme with a combined mental and physical health check, 2012-2015. Mental healthcare: psychometric test by general practitioner (GP), talk therapy by GP, contact with a psychologist, psychotropic medication or contact with a psychiatrist. Poor mental health: mental component summary score of $\leq 35.76$ (12-item Short-Form Health Survey, V.2, US norms of 1998).

health or any other red flags (table 1) were advised to book a consultation with their own GPs. Results were electronically transferred to the relevant GP and added to the individual's health record. In cases where a screening result suggested poor mental health, the GPs could provide mental healthcare themselves or they could refer the individual to secondary mental healthcare, according to national clinical guidelines. ${ }^{27}$ All but one GP in Randers Municipality participated. Individuals listed with this GP were offered a consultation by a GP in the local community health centre and referred to their own GP if further treatment was needed.

\section{Design and study population}

The present cohort study used data from the Check Your Health preventive programme and included 14167 eligible individuals who received an invitation to the Check Your Health programme within 18 April 2012-1 October 2015.

The study cohort consisted of individuals with poor mental health detected at the health check who had not received mental healthcare in the year preceding the health check. As seen in figure 1, individuals who did not participate in the mental and physical health check were excluded $(n=6819,48 \%)$. Thirteen individuals were excluded due to death, emigration or data protection regulations. A total of $645(9 \%)$ individuals were identified with poor mental health (defined later) at the health check; 295 of these had received mental healthcare within the preceding year and were excluded from the actual analyses. This left a cohort of 350 individuals with a screening result suggesting poor mental health and no mental healthcare provided in the preceding year (figure 1). Each individual was followed for 12 months. The use of national registers ensured complete follow-up data.

\section{Data sources}

We obtained information on mental health, general health, alcohol risk behaviour and smoking status from the health check survey, which participants were requested to complete electronically before attending the clinical examination. Survey data and clinical data from Check Your Health were linked to data in the Danish registers through each individual's unique personal identification number, which is assigned to all individuals with permanent residence in Denmark. ${ }^{28}$

\section{Mental health screening}

The mental health status was assessed at the screening by the mental component summary (MCS) score, which is part of the 12-item Short-Form Health Survey (SF-12) V.2. ${ }^{29}$ The SF-12 is a condensed and validated version of the SF-36, which is an acknowledged and widely used multifactorial measure of generic health-related quality of life in the general population. ${ }^{30-32}$ The SF-12 has been validated in the population of the Central Denmark Region, ${ }^{31}$ where Randers Municipality is located, and the SF-12 is used in Danish national and regional health surveys. The MCS score provides a generic measure of mental health status based on general self-rated health, mood and anxiety symptoms, and functional limitations during the past 4 weeks. ${ }^{29}$ The MCS score has been suggested useful for screening for common mental disorders. ${ }^{33}$ An MCS score of $<36$ has been shown to have a sensitivity of 0.62 for any depressive disorder and of 0.73 for generalised anxiety disorder in a general population aged 32-58 years. ${ }^{34}$ Thus, the MCS measures more than just mental disorders and is considered a valid measure of mental health status in population studies. ${ }^{30} 32$ The calculation of MCS scores was based on 1998 general US population norms and was performed only for complete SF-12 data. ${ }^{30}$ MCS scores range from 0 to 100 on a continuous scale, and a higher score reflects better mental health.

Poor mental health was defined as an MCS score of $\leq 35.76$ based on a Danish national health survey, where poor mental health corresponded to the $10 \%$ of the Danish adult population with the lowest MCS scores. ${ }^{35}$

\section{Mental healthcare}

A total of $98 \%$ of the population in Denmark are listed with a GP. ${ }^{36}$ Mental healthcare is generally free of charge for the patient, except for psychological therapy and pharmaceuticals, which both require an out-of-pocket fee. The public healthcare system covers mental health services from the GP (psychometric testing and talk therapy), $60 \%$ of the psychologist fee for patients who fulfil certain referral criteria and partial payment for prescription medication. If referred by the GP, patients can also get psychiatric specialist care free of charge. 
Table 2 Types of health services and treatments included in the definition of 'mental healthcare'

\begin{tabular}{|c|c|c|}
\hline $\begin{array}{l}\text { Type of mental } \\
\text { healthcare }\end{array}$ & Register & Details \\
\hline $\begin{array}{l}\text { Psychometric test } \\
\text { by GP }\end{array}$ & NHSR & Approved psychometric tests, for example, diagnostic tests for depression or anxiety. \\
\hline Talk therapy by GP & NHSR & $\begin{array}{l}\text { Talk therapy by GPs under psychological supervision, maximum of } 7 \text { sessions per year for } \\
\text { each patient. }\end{array}$ \\
\hline $\begin{array}{l}\text { Contact with a } \\
\text { psychologist }\end{array}$ & NHSR & Psychologists with a collective agreement with the public healthcare system. \\
\hline $\begin{array}{l}\text { Psychotropic } \\
\text { medication }\end{array}$ & DNPR & $\begin{array}{l}\text { Redeemed prescriptions of the following medications (ATC codes): antipsychotics } \\
\text { (N05A), anxiolytics (N05B), hypnotics and sedatives (N05C), antidepressants (N06A), } \\
\text { psychostimulant medication (N06B), and antidementia drugs (N06D). }\end{array}$ \\
\hline $\begin{array}{l}\text { Contact with a } \\
\text { psychiatrist }\end{array}$ & $\begin{array}{l}\text { NHSR } \\
\text { NPR }\end{array}$ & $\begin{array}{l}\text { Private psychiatrists with a collective agreement with the public healthcare system. } \\
\text { Psychiatric hospitals and outpatient clinics. }\end{array}$ \\
\hline
\end{tabular}

ATC, Anatomical Therapeutic Chemical Classification; DNPR, Danish National Prescription Register; GP, general practitioner; NHSR, Danish National Health Service Register; NPR, Danish National Patient Register.

'Mental healthcare' was defined as at least one of the following types of intervention recorded in the Danish national health registers: psychometric testing by GP (Danish National Health Service Register (NHSR) ${ }^{37}$ ), talk therapy by GP (NHSR), contact with a psychologist (NHSR), contact with a psychiatrist (NHSR and Danish National Patient Register) ${ }^{38}$ or redemption of psychotropic medication (Danish National Prescription Register) ${ }^{39}$ (table 2).

'Initiation of mental healthcare' was defined as initiation of any type of mental healthcare registered within 1 year after the date of the mental health screening.

\section{Clinical measures}

Clinical measures were obtained by trained healthcare staff using standardised methods, for example, height measured with heels touching the wall at deep inspiration; and mean systolic and diastolic blood pressure calculated from three measures on the left arm with 1 min intervals after 5 min rest. ${ }^{27}$ Blood pressure was measured with Omron M6 (Omron Healthcare Europe). Cholesterol and low-density lipoprotein were measured by finger blood test with Alere Cholestech LDX System (Alere Denmark). Glycated haemoglobin was measured by finger blood test with DCA Vantage Analyzer (Siemens Healthcare, Siemens, Germany). Ten-year risk of fatal cardiovascular disease was calculated with the Systematic Coronary Risk Evaluation European Low Risk Chart based on sex, age, systolic blood pressure, total cholesterol and smoking status and was extrapolated to age 60 years. ${ }^{40}$ Lung function (forced expiratory volume in $1 \mathrm{~s}$ and forced vital capacity) was measured with the EasyOne Diagnostic Spirometer (ndd Medical Technologies, Andover, Massachusetts, USA).

From April 2012 to July 2013, we calculated alcohol risk behaviour using the four-item Cut down, Annoyed, Guilty, Eye-opener (Copenhagen) questionnaire. ${ }^{41}$ From August 2013, the Alcohol Use Disorders Identification Test (AUDIT) ${ }^{42}$ was used because AUDIT was implemented in the national guidelines to GPs. We dichotomised selfrated general health (SF-12 item 1) ${ }^{29}$ into poor/fair and good (good, very good or excellent).

The Check Your Health steering committee (including GPs) decided that poor mental health or any of the other red flags listed in table 1 should prompt a recommendation for a follow-up consultation with the GP. ${ }^{27}$

\section{Sociodemographic variables}

We obtained all sociodemographic variables within the year before invitation from administrative national registers managed by Statistics Denmark. ${ }^{43}$ The sociodemographic explanatory variables used were sex, age, ethnicity, education, employment, cohabitation status and income as these were the most frequently examined variables in studies of healthcare utilisation. ${ }^{44}$ We grouped country of origin into Western or non-Western. We categorised educational level into $\leq 10,11-15$ and $>15$ years of education according to the International Standard Classification of Education by UNESCO. ${ }^{45}$ We grouped occupational status into employed, unemployed/benefits (unemployed at least half of the year or receiving sickness/parental benefit) or social welfare (early disability pension or social security benefits). We dichotomised cohabitation into cohabiting (married or living with a partner) or living alone (including widows and divorced). We calculated equivalence-weighted household income as recommended by the Organisation for Economic Co-operation and Development, ${ }^{46}$ and we categorised income into tertiles. We gained information on vital status from the Danish Register of Causes of Death ${ }^{47}$ and information on emigration from the Danish Civil Registration System. $^{28}$

\section{Patient and public involvement}

Patients or the public were not involved in the design, or conduct, or reporting or dissemination plans of our research. 


\section{Statistics}

Descriptive statistics were reported as proportion (n, $\%$ ) (categorical variables) or mean and SD (continuous variables). Results with less than five observations were reported as ' $<5$ ' due to data protection regulations (anonymity). ${ }^{48}$ Univariate and multiple logistic regression models were used to estimate OR for the association between explanatory variables and initiation of mental healthcare' within a follow-up time of 12 months from each individual's mental health screening.

The explanatory variables included severity of the mental health condition (the MCS score (continuous) ), ${ }^{2122}$ sociodemographic factors ${ }^{21} 23-25$ and red flags (besides poor mental health) at the health check.

To investigate whether the impact of each explanatory variable on initiation of mental healthcare was confounded, we adjusted each explanatory variable for potential confounders in separate multiple logistic regression analyses. ${ }^{50}$ The potential confounders for each explanatory variable were chosen a priori: sex, age, education and cohabitation were mutually adjusted. Occupation and income were adjusted for sex, age and cohabitation. All other explanatory variables were adjusted for sex, age, education and cohabitation. (As educational level, occupational status and income are correlated, we did not include educational level in the multiple logistic regression models with occupational status and income as explanatory variables because this might have led to overadjustment. ${ }^{51}$ ) All models were run as complete case analyses, meaning only participants with information on all variables in the specific model were included in the analysis. Hence the number of participants in the separate multiple logistic regression models varied from 331 to 350 (online supplemental table A).

All estimates were reported with $95 \%$ CI. P values $<0.05$ were considered statistically significant.

We performed all statistical analyses on the remote server of Statistics Denmark using Stata V.15.1 software.

\section{RESULTS}

\section{Description of cohort}

The study cohort consisted of individuals with screendetected poor mental health who had not received mental healthcare within the year preceding the screening $(\mathrm{N}=350)$ (figure 1). Table 3 shows that $43 \%$ of the cohort were men. The mean age was 39.0 years (SD 5.5). One in five $(n=71)$ had low level of education ( $0-10$ years $)$, one in three $(n=120)$ had high level of education ( $>15$ years $)$, and the remaining individuals $(n=152)$ had medium level of education (11-15 years). Two in three lived with a partner. One in four had high income, one in three had medium income, and the remaining individuals had low income. Of the 350 individuals, one in three $(n=115)$ had frequently visited ( $\geq 5$ visits) their GP in the preceding year, whereas one in three $(n=111)$ had only one (or no) visit to their GP in the year before the health check.

\section{Initiation of mental healthcare at follow-up}

In this study, 91\% $(\mathrm{n}=319)$ contacted their GP for any reason in the year after the mental health screening (table 4$)$. About $22 \%(n=78)$ of the cohort initiated mental healthcare within 1 year of follow-up. Thus, $78 \%$ $(n=272)$ did not initiate any of the listed types of mental healthcare in the follow-up period. Among the individuals not initiating the listed types of mental healthcare, $30 \%$ reported poor or fair self-rated general health and $16 \%$ reported risky alcohol behaviour. Among the individuals who did initiate mental healthcare, $17 \%$ had none or only one contact with their GP in the preceding year. A total of $38.5 \%$ of the cohort had no red flags, besides a poor mental health screening result. Consequently, these individuals would not have been referred to the GP if the health check had not included a mental health screening.

\section{Factors associated with non-initiation of mental healthcare}

For adjusted results, we found that men (OR: 0.49 (95\% CI 0.28 to 0.86$)$ ) were less likely than women to initiate mental healthcare after the health check, and for each unit increase in the MCS score (less severe poor mental health) there was a $7 \%$ decrease in odds of initiating mental healthcare $(0.93$ (0.89 to 0.98$))$ (figure 2). Furthermore, individuals of older age $(0.98$ (0.94 to $1.03)$ ), individuals of non-Western origin $(0.57$ (0.19 to $1.74)$ ), individuals with low level of education $(0.56(0.26$ to 1.17$)$ ) and medium level of education (0.64 (0.36 to $1.15)$ ), and individuals on social welfare $(0.60$ (0.26 to 1.38)) had lower likelihood of initiating mental healthcare, but these results were not statistically significant. Being unemployed or receiving benefits (1.92 (0.82 to 4.53$)$ ), having low income $(1.54(0.75$ to 3.15$))$ and medium income (1.61 ( 0.78 to 3.35$))$, and living alone (1.70 (0.97 to 2.98$)$ ) were non-significantly associated with higher likelihood of initiating mental healthcare. Further, no clear association was seen between having other red flags besides poor mental health at the health check and initiating mental healthcare $(0.99$ (0.56 to 1.74)). The multiple regression models did not change the estimates substantially compared with the crude estimates (online supplemental table B). Estimates of all predictors in every multiple logistic regression model are seen in online supplemental table A.

\section{DISCUSSION}

\section{Main results}

To our knowledge, the present study is the first to investigate factors associated with initiation of mental healthcare among individuals with screen-detected poor mental health at a population-based health check. The study provides important information on the extent of initiation of mental healthcare despite detection of poor mental health and on factors associated with non-initiation of mental healthcare.

Among 645 individuals identified with poor mental health, 350 (54\%) had not received mental healthcare 
Table 3 Characteristics of study cohort: Check Your Health, Denmark, 2012-2015

\begin{tabular}{|c|c|c|c|}
\hline & Total & & Missing data \\
\hline & $\mathrm{n}$ & $\%(95 \% \mathrm{Cl})$ & $\mathrm{n}$ \\
\hline & 350 & 100 & \\
\hline Sex & & & 0 \\
\hline Female & 198 & 56.6 (51.4 to 61.8$)$ & \\
\hline Male & 152 & 43.4 (38.2 to 48.6$)$ & \\
\hline Age, mean (SD) & & $39.0(5.5)$ & 0 \\
\hline Country of origin & & & 0 \\
\hline Western & 315 & 90.0 (86.4 to 92.9) & \\
\hline Non-Western & 35 & $10.0(7.0$ to 13.6$)$ & \\
\hline Education (years) & & & 7 \\
\hline $0-10$ & 71 & 20.7 (16.4 to 25.0$)$ & \\
\hline $11-15$ & 152 & 44.3 (39.1 to 49.6$)$ & \\
\hline$>15$ & 120 & 35.0 (29.9 to 40.0$)$ & \\
\hline Occupational status & & & 10 \\
\hline Employed & 263 & 77.4 (72.9 to 81.8$)$ & \\
\hline Unemployed/benefits & 27 & 7.9 (5.1 to 10.8$)$ & \\
\hline Social welfare recipients & 50 & 14.7 (10.9 to 18.5$)$ & \\
\hline \multicolumn{4}{|l|}{ Cohabiting status } \\
\hline Cohabiting & 239 & 68.3 (63.4 to 73.2$)$ & \\
\hline Living alone & 111 & 31.7 (26.8 to 36.6$)$ & 0 \\
\hline Income & & & 0 \\
\hline Low & 151 & 43.1 (38.0 to 48.3 ) & \\
\hline Medium & 112 & 32.0 (27.1 to 36.9$)$ & \\
\hline High & 87 & 24.9 (20.3 to 29.4) & \\
\hline \multicolumn{3}{|c|}{ Number of contacts with GP within 1 year before health check } & 0 \\
\hline None & $47-2-2$ & 13.4 (9.9 to 17.0$)$ & \\
\hline 1 & 64 & $18.3(14.2$ to 22.3$)$ & \\
\hline $2-4$ & 124 & 35.4 (30.4 to 40.4$)$ & \\
\hline $5+$ & 115 & 32.9 (27.9 to 37.8$)$ & \\
\hline
\end{tabular}

Participants in the Check Your Health preventive programme 2012-2015 identified with poor mental health through screening who had not received mental healthcare within 1 year prior to the health check.

Poor mental health: MCS score of $\leq 35.76$ (from SF-12, V.2, US norms of 1998).

Mental healthcare: psychometric test by GP, talk therapy by GP, contact with a psychologist, contact with a psychiatrist or psychotropic medication.

GP, general practitioner; MCS, mental component summary; SF-12, 12-item Short-Form Health Survey.

within the year preceding the health check. Among the 350 individuals, one in five initiated mental healthcare within the following 12 months. Among individuals who initiated mental healthcare, one in six were rare visitors to their GP (0-1 contact) in the preceding year. Initiation of mental healthcare was especially low for men and those with less severe poor mental health. We found no overall association between socioeconomic factors or having red flags and initiating mental healthcare.

\section{Comparison with other studies}

The effectiveness of screening for mental disorders in the primary care setting has previously been studied. ${ }^{12-14}$
However, few studies have focused on initiation of mental healthcare among newly identified screen-positive individuals. ${ }^{18-20}$

Initiation of mental healthcare following populationbased $^{18}$ or GP-based ${ }^{19}{ }^{20}$ screening ranges from $16 \%{ }^{19}$ to $42 \% .{ }^{20}$ The studies differ in three important ways.

First, screening tools varied from diagnostic tests for depressive disorders ${ }^{1820}$ to identification of a broad range of mental health problems, including subthreshold or probable diagnoses. ${ }^{19}$ Next, the outcome varied from a similar definition of mental healthcare ${ }^{18}$ to prescriptions of psychotropic medication only, ${ }^{19}$ which may partly 
Table 4 Health check results and initiation of mental healthcare within follow-up (no/yes), Check Your Health, Denmark, 20122015

Initiation of mental healthcare within 1 year of

follow-up

\begin{tabular}{|c|c|c|c|c|c|c|c|}
\hline & \multicolumn{2}{|l|}{ No } & \multicolumn{2}{|l|}{ Yes } & \multicolumn{2}{|l|}{ Total } & \multirow{2}{*}{$\begin{array}{l}\text { Missing } \\
\text { data } \\
\mathrm{n}\end{array}$} \\
\hline & $\mathrm{n}$ & $\%(95 \% \mathrm{Cl})$ & $\mathrm{n}$ & $\%(95 \% \mathrm{Cl})$ & $\mathrm{n}$ & $\%(95 \% \mathrm{Cl})$ & \\
\hline \multicolumn{8}{|l|}{ Mental health severity } \\
\hline MCS, mean (SD) & & $30.1(5.1)$ & & $28.4(5.4)$ & & $29.7(5.2)$ & 0 \\
\hline Poor/fair self-rated health & 82 & 30.1 (24.7 to 35.6$)$ & 34 & 43.6 (32.6 to 54.6$)$ & 116 & 33.1 (28.2 to 38.1$)$ & 0 \\
\hline Alcohol risk behaviour & 41 & 15.9 (11.4 to 20.4$)$ & 7 & 9.3 (2.7 to 15.9$)$ & 48 & 14.4 (10.6 to 18.2$)$ & 17 \\
\hline CVD/DM high-risk profile & 74 & 28.1 (22.7 to 33.6 ) & 11 & 14.7 (6.7 to 22.7$)$ & 85 & 25.1 (20.5 to 29.8$)$ & 12 \\
\hline Reduced lung function & 60 & 23.1 (18.0 to 28.2 ) & 10 & 14.1 (6.0 to 22.2$)$ & 70 & 21.1 (6.0 to 22.2$)$ & 19 \\
\hline
\end{tabular}

Participants in the Check Your Health preventive programme 2012-2015 identified with screen-detected poor mental health who had not received mental healthcare within 1 year prior to the health check.

Poor mental health: MCS score of $\leq 35.76$ (from SF-12, V.2, US norms of 1998).

Mental healthcare: psychometric test by GP, talk therapy by GP, contact with psychologist, contact with psychiatrist or psychotropic medication.

*Any red flag besides poor mental health screening result: poor/fair self-rated health (SF-12 item 1); alcohol risk behaviour (CAGE-C ( $\geq 2$ positive answers to items 1-4 and 6, or one positive answer to items 1-4 and 6, plus alcohol intake on $\geq 4$ days per week); AUDIT score $\geq 8$ or $\geq 21$ number of alcohol units per week (men), or AUDIT score $\geq 8$ or $\geq 14$ number of alcohol units per week (women)); high CVD/DM risk profile (systolic BP $\geq 140$, diastolic BP $\geq 95, \mathrm{HbA} 1 \mathrm{c} \geq 6.0 \%$, total cholesterol $\geq 6 \mathrm{mmol} / \mathrm{L}$, LDL $\geq 6 \mathrm{mmol} / \mathrm{L}$ or 10 -year risk of fatal CVD $\geq 5 \%$ ); and reduced lung function ( $\mathrm{FEV}_{1}$ or $\mathrm{FVC} \leq 80 \%$ or $\mathrm{FEV}_{1} / \mathrm{FVC} \leq 0.70$ ).

†Not stratified on initiation of mental healthcare within 1 year of follow-up due to data protection regulation $(n<5)$.

AUDIT, Alcohol Use Disorders Identification Test; BP, blood pressure; CAGE-C, Cut down, Annoyed, Guilty, Eye-opener (Copenhagen); CVD, cardiovascular disease; DM, diabetes mellitus; $\mathrm{FEV}_{1}$, forced expiratory volume in $1 \mathrm{~s}$; FVC, forced vital capacity; GP, general practitioner; HbA1c, glycated haemoglobin; LDL, low-density lipoprotein; MCS, mental component summary; SF-12, 2-item Short-Form Health Survey.

explain the lower proportion of initiation in the study by Williams et al. ${ }^{19}$ Finally, the personalised feedback, and a recommendation to discuss mental health with the individual's GP, as provided in the Check Your Health programme, may have played a substantial role in the initiation of mental healthcare in our study. In the study by Packness $e t a l,{ }^{18}$ there was no report to the individual or to the GP on the test result, whereas the intervention in the study by Rost $e t a l^{20}$ was more comprehensive than in Check Your Health. This may explain the large extent of initiation of mental healthcare in the study by Rost et al. ${ }^{20}$

Several studies support our findings that less severe mental health problems are associated with lower use of mental healthcare. ${ }^{21}{ }^{22}$ Not seeking mental healthcare despite a need has previously been explained by barriers related to acceptability, accessibility and availability of services. ${ }^{52}$ Previous studies support our findings that men are less likely to use mental healthcare. ${ }^{21}{ }^{23}$ Our results further indicate that the association was not confounded by socioeconomic factors. That men are less likely to use mental healthcare could be explained by acceptability barriers; many men may prefer to manage mental health problems themselves or believe that seeking treatment will not help. ${ }^{52} 53$
We found no clear overall association between socioeconomic factors and initiating mental healthcare, which may be explained by free and equal access to general practice in Denmark. ${ }^{36}$ This could indicate that no social inequality was seen in the mental healthcare provided after the health check, which would imply that Check Your Health does not contribute to social inequality in mental healthcare. However, these results must be taken with precaution because of the wide CIs due to small subgroups. Furthermore, persons with more disadvantageous socioeconomic characteristics were less likely to participate in the Check Your Health programme. ${ }^{54}$ The literature on the associations between socioeconomic characteristics and mental healthcare has shown inconsistent results. ${ }^{21} 23245255$ This might be explained by differences in the accessibility to mental healthcare in the healthcare systems and variations in the severity of mental health problems. Accessibility barriers, such as costs and lack of transportation, ${ }^{52}$ may partly explain our findings that individuals on social welfare benefits tended to be less likely to initiate mental healthcare. However, low income was in our results (statistically non-significantly) associated with being more likely to initiate mental healthcare and would oppose this argument. Although statistically 


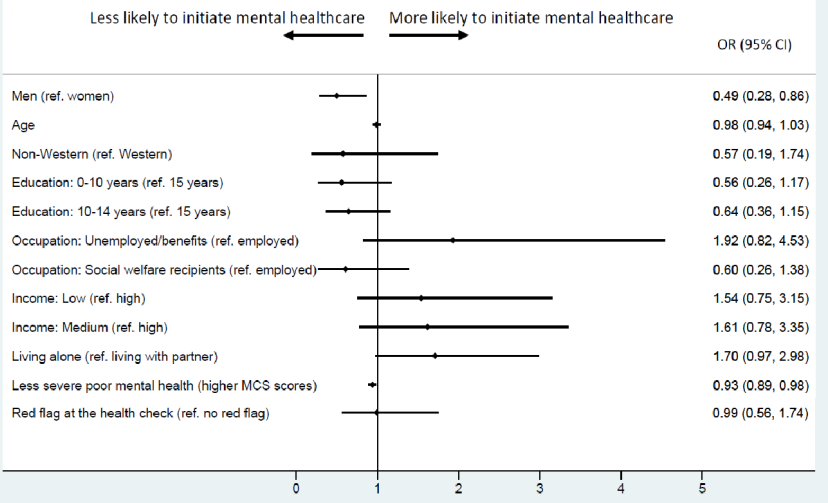

Figure 2 Factors associated with initiation and non-initiation of mental healthcare after health check $(\mathrm{N}=350)$. Adjusted ORs. Participants of the Check Your Health preventive programme in 2012-2015 with screen-detected poor mental health who had not received mental healthcare within the year preceding the health check. Age is adjusted for sex, education and cohabitation. Sex is adjusted for age, education and cohabitation. Education, occupation and income are adjusted for sex, age and cohabitation. All other explanatory variables are adjusted for sex, age, education and cohabitation. Red flags at the health check: any red flag besides poor mental health screening result: poor/ fair self-rated health (SF-12 item 1); alcohol risk behaviour (CAGE-C ( $\geq 2$ positive answers to items $1-4$ and 6 , or one positive answer to items $1-4$ and 6 , plus alcohol intake on $\geq 4$ days per week), AUDIT score $\geq 8$ or $\geq 21$ number of alcohol units per week (men), or AUDIT score $\geq 8$ or $\geq 14$ number of alcohol units per week (women)); high CVD/DM risk profile (systolic $\mathrm{BP} \geq 140$, diastolic $\mathrm{BP} \geq 95, \mathrm{HbA} 1 \mathrm{c} \geq 6.0 \%$, total cholesterol $\geq 6 \mathrm{mmol} / \mathrm{L}$, LDL $\geq 6 \mathrm{mmol} / \mathrm{L}$ or 10 -year risk of fatal $\mathrm{CVD} \geq 5 \%$ ); and reduced lung function ( $\mathrm{FEV}_{1}$ or $\mathrm{FVC} \leq 80 \%$ or $\mathrm{FEV}_{1} / \mathrm{FVC} \leq 0.70$ ). (Part of the figure was made with Stata V.15.1 software on the remote server of Statistics Denmark. Downloaded with permission from Statistics Denmark.) AUDIT, Alcohol Use Disorders Identification Test; BP, blood pressure; CAGE-C, Cut down, Annoyed, Guilty, Eye-opener (Copenhagen); CVD, cardiovascular disease; DM, diabetes mellitus; $F_{E V}$, forced expiratory volume in $1 \mathrm{~s}$; FVC, forced vital capacity; HbA1c, glycated haemoglobin; LDL, lowdensity lipoprotein; MCS, mental component summary; SF12, 12-item Short-Form Health Survey.

non-significant, we found that people living alone might be more likely to initiate mental healthcare. Previous studies have found an association between living alone and receiving mental healthcare. ${ }^{21} 23$ This can partly be explained by that individuals living alone generally have a higher level of mental health problems, ${ }^{56}$ but also because individuals living alone may lack support and a close relative to talk to.

Although most individuals had contact with their GP for any reason during follow-up, we found no association between red flags and initiation of mental healthcare. As previously mentioned, we had no information on the content of the consultations, so we cannot know how many actually did have some kind of non-recorded psychological support by GP. Although wide CIs may have masked an association, explanations may be the stigma associated with mental health problems or the individual's wish to manage the problem by themselves. ${ }^{57}$ It may also be that the GPs have too few resources to handle complex health issues, such as combined mental and physical health problems, and the GP may prefer to address the physical problems. ${ }^{59}$

\section{Strengths and limitations of this study}

Study cohort

A major strength was that the study was based on data from a large-scale intervention programme implemented in the existing healthcare system. The results thus provide a realistic picture of factors associated with non-initiation of mental healthcare after screen-detected poor mental health. The large population size $(n=14167)$ allowed us to focus on individuals with poor mental health who had not received mental healthcare in the year preceding the health check.

A limitation of focusing on a subgroup is the large CIs, and we may thus have overlooked true associations. In addition, the small number of observations allowed us to adjust for only a limited number of confounders.

\section{National registers}

A strength of the present study was the use of national registers, which provided complete and valid follow-up data on the use of mental healthcare for all participants in the study. A limitation of using register data is that the registers do not contain information on all types of support, for example, non-recorded psychological support by the GP, self-financed psychologist consultations or alternative mental healthcare providers. Therefore, our results may have underestimated the extent of the actual mental healthcare provided after the health check.

\section{Mental health screening}

A strength of using the MCS score for mental health screening is that this tool is useful for detecting mental disorders, $^{33}$ and the MCS score is correlated with disability. ${ }^{60}$ In addition, it has been shown to be useful in identifying persons with functional impairment caused by subthreshold mental health problems. ${ }^{33}$ This implies that we also identified individuals in potential need of minor intervention, for example, psychological support by the GP.

A challenge of using the MCS score is that all items must be completed to calculate the score. We have previously shown that $7 \%$ of participants of the Check Your Health who completed parts of the health survey did not get an MCS score. ${ }^{61}$ These SF-12 non-respondents were more likely to have disadvantaged socioeconomic characteristics, ${ }^{61}$ and a fair proportion of this group may suffer from mental distress. ${ }^{5}$

\section{Initiation of mental healthcare}

Additional factors could have influenced initiation of mental healthcare, such as the individual's health literacy 
and attitudes towards handling of mental health problems. These factors have previously been shown to have large impact on help-seeking for mental health problems. ${ }^{52}$ Moreover, organisational and structural factors, such as time restrictions, lack of training in mental health issues and limited referral resources, may have caused non-initiation of mental healthcare among the GPs. ${ }^{62}$ This information was not available in the present study.

Further, additional information on diagnoses or level of severity was not available. Such information may more precisely have indicated the actual need of mental healthcare.

A general limitation of observational studies (including the present study) is that no firm conclusion can be drawn on causal relations. Hence, we do not know to which extent the individuals might have sought treatment anyway, regardless of participation in the health check. However, $17 \%$ of those who did initiate mental healthcare had none or only one contact with their GP in the preceding year. Thus, it seems less likely that they have discussed their mental health with the GP before the health check, and it is likely that the health check had an impact on their help-seeking.

Despite these limitations, the present study identifies factors that deserve attention in similar future initiatives in order to improve the provision of mental healthcare.

\section{Generalisability}

The health profile of citizens in Randers Municipality, where the health check was conducted, has been rated as average compared with the general population in Denmark. ${ }^{63}$ However, participants in the Check Your Health preventive programme were more likely to be older, to have more advantageous socioeconomic characteristics and to be healthier than non-participants. ${ }^{54}$ One study from the British National Health Service health check suggested that no social inequalities exist in the participation in health checks, ${ }^{64}$ but several European studies have reported social inequality in participation rates. ${ }^{65-67}$ This suggests that the study cohort in the Check Your Health preventive programme is expected to be representative of the population in a preventive health check in a population-based setting.

The observed results may be generalisable to other countries with a similar organisation of healthcare and similar referral patterns to specialist mental healthcare. However, the study focused on individuals aged 30-49 years, and the results may not apply to other age groups.

\section{Implications and future research}

The present study identified factors associated with noninitiation of mental healthcare in individuals with screendetected mental health problems. The results point to groups of individuals who may deserve special attention in similar future initiatives. Future research may investigate whether another recruitment strategy targeting the groups identified in the study could improve the initiation of mental healthcare, for example, introducing men to action-focused interventions based on problem-solving strategies ${ }^{68}$ and offering 'low-intensity' interventions, for example, guided self-help or computerised cognitive-behavioural therapy in order to improve mental healthcare among individuals with mild to moderate mental health problems. ${ }^{69}{ }^{70}$ Collaborative care between general practice and specialised mental health services, ${ }^{71}$ combined with easy access to psychological therapy ${ }^{72}$ may further support the initiation of mental healthcare after identification of poor mental health, but this must be investigated further.

\section{CONCLUSION}

A population-based health check can identify a considerable number of individuals as being likely to have a mental health problem. Our findings indicate no overall socioeconomic inequality in initiation of mental healthcare among participants. However, most screen-positive individuals did not engage in mental healthcare within the following year, even though feedback on the test results was given to both the individual and to the GP.

Much more than screening is required if we are to improve mental healthcare for adults. New efforts should target groups that are less likely to initiate mental healthcare, such as men with poor mental health.

Acknowledgements We would like to thank the participants of the Check Your Health preventive programme for their contributions, the staff at Randers Health Centre for performing the clinical examinations, the participating GPs for performing the health consultations, Marianne Pedersen for managing the data, Kasper Norman for project administration, Niels Henrik Bruun for assistance with the statistical analyses and Lone Niedziella for linguistic revision.

Contributors CG, KSC, E-MD, BHB, HTM and AS contributed to developing the design of the study. CG, KSC, E-MD, BHB, HTM, JG and AS contributed to interpreting the data and critical revision of the scientific paper. CG is the guarantor of this work and assumes full responsibility for the conduct of the study. CG had access to the data and controlled the decision to publish.

Funding This work was supported by the Danish foundation TrygFonden (grant number 7-11-0500), the Health Foundation (grant number 15-B-0165) and the Danish General Practice Fund (grant number EMN-2017-00265).

Competing interests JG reports personal fees from the Eastern Melbourne Primary Health Network (outside the submitted work).

Patient consent for publication Not required.

Ethics approval Written consent was obtained from all participants in the study. The study was registered with the Danish Data Protection Agency under the joint notification of research projects at Aarhus University (file no: 2015-57-0002). Since the study was based on data from the ongoing Check Your Health programme, no approval by the National Committee on Health Research Ethics was required.

Provenance and peer review Not commissioned; externally peer reviewed.

Data availability statement Data may be obtained from a third party and are not publicly available. All data analysed in the study were deidentified and securely stored at the remote server of Statistics Denmark. Data sets are available after formal application to Statistics Denmark.

Supplemental material This content has been supplied by the author(s). It has not been vetted by BMJ Publishing Group Limited (BMJ) and may not have been peer-reviewed. Any opinions or recommendations discussed are solely those of the author(s) and are not endorsed by BMJ. BMJ disclaims all liability and responsibility arising from any reliance placed on the content. Where the content includes any translated material, BMJ does not warrant the accuracy and reliability of the translations (including but not limited to local regulations, clinical guidelines, 
terminology, drug names and drug dosages), and is not responsible for any error and/or omissions arising from translation and adaptation or otherwise.

Open access This is an open access article distributed in accordance with the Creative Commons Attribution Non Commercial (CC BY-NC 4.0) license, which permits others to distribute, remix, adapt, build upon this work non-commercially, and license their derivative works on different terms, provided the original work is properly cited, appropriate credit is given, any changes made indicated, and the use is non-commercial. See: http://creativecommons.org/licenses/by-nc/4.0/.

\section{ORCID iDs}

Christine Geyti http://orcid.org/0000-0002-3046-4901

Kaj Sparle Christensen http://orcid.org/0000-0002-0409-2702

Else-Marie Dalsgaard http://orcid.org/0000-0003-2115-7480

Bodil Hammer Bech http://orcid.org/0000-0002-0287-3687

Jane Gunn http://orcid.org/0000-0001-8836-7525

Helle Terkildsen Maindal http://orcid.org/0000-0003-0525-7254

Annelli Sandbaek http://orcid.org/0000-0003-1647-2646

\section{REFERENCES}

1 World Health Organization, Regional Office for Europe. The European mental health action plan 2013-2020. Copenhagen: World Health Organization, 2015.

2 Whiteford HA, Degenhardt L, Rehm J, et al. Global burden of disease attributable to mental and substance use disorders: findings from the global burden of disease study 2010. Lancet 2013;382:1575-86.

3 Moussavi S, Chatterji S, Verdes E, et al. Depression, chronic diseases, and decrements in health: results from the world health surveys. Lancet 2007;370:851-8.

4 Ferrari AJ, Charlson FJ, Norman RE, et al. Burden of depressive disorders by country, sex, age, and year: findings from the global burden of disease study 2010. PLoS Med 2013;10:e1001547.

5 Pinto-Meza A, Moneta MV, Alonso J, et al. Social inequalities in mental health: results from the EU contribution to the world mental health surveys initiative. Soc Psychiatry Psychiatr Epidemiol 2013;48:173-81.

6 Gustavsson A, Svensson M, Jacobi F, et al. Cost of disorders of the brain in Europe 2010. Eur Neuropsychopharmacol 2011;21:718-79.

7 Region Midtjylland [Central Denmark Region]. Psykiatriplan: Bedre behandling og længere liv til flere med psykisk sygdom på patientens præmisser - Psykiatriplan for Region Midtjylland 2017 [Psychiatry plan: Better treatment and longer life to more patients with psychiatric disease on the patient's terms - Psychiatry plan for Central Denmark Region 2017. Central Denmark Region: Viborg, 2017.

8 Ohayon MM, Priest RG, Guilleminault C, et al. The prevalence of depressive disorders in the United Kingdom. Biol Psychiatry 1999:45:300-7.

9 Ministry of Health. Partnerskabsaftale "Mental sundhed på arbejdspladsen" [Partnership agreement "Mental health at the workplace". Copenhagen: Ministry of Health, 2016.

10 Mitchell AJ, Vaze A, Rao S. Clinical diagnosis of depression in primary care: a meta-analysis. Lancet 2009;374:609.

11 Cassano P, Fava M. Depression and public health: an overview. J Psychosom Res 2002;53:849-57.

12 Gilbody S, Sheldon T, House A. Screening and casefinding instruments for depression: a meta-analysis. CMAJ 2008;178:997-1003.

13 Gidding LG, Spigt M, Winkens B, et al. PsyScan e-tool to support diagnosis and management of psychological problems in general practice: a randomised controlled trial. $\mathrm{Br} J$ Gen Pract 2018;68:e18-27.

14 Palmer SC, Coyne JC. Screening for depression in medical care: pitfalls, alternatives, and revised priorities. J Psychosom Res 2003;54:279-87.

15 Christensen KS, Sokolowski I, Olesen F. Case-Finding and risk-group screening for depression in primary care. Scand J Prim Health Care 2011;29:80

16 MaGPle Research Group. The effectiveness of case-finding for mental health problems in primary care. Br J Gen Pract 2005;55:665-9.

17 Siu AL, Bibbins-Domingo K, et al, US Preventive Services Task Force (USPSTF). Screening for depression in adults: US preventive services Task force recommendation statement. JAMA 2016;315:380-7.

18 Packness A, Halling A, Hastrup LH, et al. Socioeconomic position, symptoms of depression and subsequent mental healthcare treatment: a Danish register-based 6-month follow-up study on a population survey. BMJ Open 2018;8:e020945.

19 Williams JB, Spitzer RL, Linzer M, et al. Gender differences in depression in primary care. Am J Obstet Gynecol 1995;173:654-9.

20 Rost K, Nutting P, Smith J, et al. Improving depression outcomes in community primary care practice: a randomized trial of the quEST intervention. quality enhancement by strategic Teaming. J Gen Intern Med 2001;16:143-9.

21 Ten Have M, Nuyen J, Beekman A, et al. Common mental disorder severity and its association with treatment contact and treatment intensity for mental health problems. Psychol Med 2013;43:2203.

22 Bruffaerts R, Posada-Villa J, Al-Hamzawi AO, et al. Proportion of patients without mental disorders being treated in mental health services worldwide. Br J Psychiatry 2015;206:101-9.

23 Bijl RV, Ravelli A. Psychiatric morbidity, service use, and need for care in the general population: results of the Netherlands mental health survey and incidence study. Am J Public Health 2000;90:602-7.

24 Packness A, Waldorff FB, Christensen RdePont, et al. Impact of socioeconomic position and distance on mental health care utilization: a nationwide Danish follow-up study. Soc Psychiatry Psychiatr Epidemiol 2017;52:1405-13.

25 Boerema AM, Ten Have M, Kleiboer A, et al. Demographic and need factors of early, delayed and NO mental health care use in major depression: a prospective study. BMC Psychiatry 2017;17:367.

26 Kessler RC, Angermeyer M, Anthony JC, et al. Lifetime prevalence and age-of-onset distributions of mental disorders in the world Health organization's world mental health survey initiative. World Psychiatry 2007;6:168-76.

27 Maindal HT, Støvring H, Sandbaek A. Effectiveness of the population-based Check your health preventive programme conducted in primary care with 4 years follow-up [the CORE trial]: study protocol for a randomised controlled trial. Trials 2014;15:341.

28 Pedersen CB. The Danish civil registration system. Scand J Public Health 2011;39:22-5.

29 Ware J, Kosinski M, Keller SD. A 12-Item short-form health survey: construction of scales and preliminary tests of reliability and validity. Med Care 1996;34:220-33.

30 Ware JE, Kosinski M, Turner-Bowker DM, et al. User's manual for the SF-12v2@ health survey with a supplement documenting the SF-12® health survey. QualityMetric incorporated: Lincoln, RI, 2002.

31 Christensen LN, Ehlers L, Larsen FB, et al. Validation of the 12 item short form health survey in a sample from region central Jutland. Soc Indic Res 2013:114:513-21.

32 Kontodimopoulos N, Pappa E, Niakas D, et al. Validity of SF-12 summary scores in a Greek general population. Health Qual Life Outcomes 2007;5:55.

33 Gill SC, Butterworth P, Rodgers B, et al. Validity of the mental health component scale of the 12-Item short-form health survey (MCS-12) as measure of common mental disorders in the general population. Psychiatry Res 2007:152:63-71.

34 Kiely KM, Butterworth P. Validation of four measures of mental health against depression and generalized anxiety in a community based sample. Psychiatry Res 2015;225:291-8.

35 Christensen Al, Davidsen M, Kjøller M, et al. Mental sundhed blandt voksne danskere: analyser baseret på sundheds- og sygelighedsundersøgelsen 2005 [Mental health among adult Danes: analyses based on the Danish health and morbidity survey 2005. Copenhagen: The Danish Health Authority, 2010: 90.

36 Christiansen T. Organization and financing of the Danish health care system. Health Policy 2002;59:107-18.

37 Andersen JS, Olivarius NDF, Krasnik A. The Danish National health service register. Scand J Public Health 2011;39:34-7.

38 Lynge E, Sandegaard JL, Rebolj M. The Danish national patient register. Scand J Public Health 2011;39:30-3.

39 Kildemoes HW, Sørensen HT, Hallas J. The Danish national prescription registry. Scand J Public Health 2011;39:38-41.

40 Perk J, De Backer G, Gohlke H, et al. European guidelines on cardiovascular disease prevention in clinical practice (version 2012). The fifth joint Task force of the European Society of cardiology and other societies on cardiovascular disease prevention in clinical practice (constituted by representatives of nine societies and by invited experts). Eur Heart J 2012;33:1635.

41 Zierau F, Hardt F, Henriksen JH, et al. Validation of a selfadministered modified cage test (CAGE-C) in a somatic Hospital ward: comparison with biochemical markers. Scand J Clin Lab Invest 2005;65:615-22.

42 Saunders JB, Aasland OG, Babor TF, et al. Development of the Alcohol Use Disorders Identification Test (AUDIT): WHO Collaborative Project on Early Detection of Persons with Harmful Alcohol Consumption--II. Addiction 1993;88:791-804. 
43 Statistics Denmark. Data for research Copenhagen: statistics Denmark. Available: http://www.dst.dk/en/TilSalg/Forskningsservice [Accessed 11 Aug 2020].

44 Babitsch B, Gohl D, von Lengerke T. Re-revisiting Andersen's behavioral model of health services use: a systematic review of studies from 1998-2011. Psychosoc Med 2012;9:Doc11.

45 Unesco. International standard classification of education 1997. United Nations Educational, Scientific and Cultural Organization, 1997.

46 OECD. Mental health and work: Denmark. Paris: OECD Publishing, 2013.

47 Helweg-Larsen K. The Danish register of causes of death. Scand J Public Health 2011;39:26-9.

48 Statistics Denmark. Guidelines for transferring aggregated results from Statistics Denmark's research services, 2015.

49 European Commission. Communication from the commission to the European parliament and the council. Stronger protection, new opportunities - Commission guidance on the direct application of the General Data Protection Regulation as of 25 May 2018. Brussels: European Commission, 2018.

50 Westreich D, Greenland S. The table 2 fallacy: presenting and interpreting confounder and modifier coefficients. Am J Epidemiol 2013;177:292-8.

51 Shavers VL. Measurement of socioeconomic status in health disparities research. J Natl Med Assoc 2007;99:1013.

52 Steele L, Dewa C, Lee K. Socioeconomic status and selfreported barriers to mental health service use. Can J Psychiatry 2007;52:201-6.

53 Möller-Leimkühler AM. Barriers to help-seeking by men: a review of sociocultural and clinical literature with particular reference to depression. J Affect Disord 2002;71:1-9.

54 Bjerregaard A-L, Maindal HT, Bruun NH, et al. Patterns of attendance to health checks in a municipality setting: the Danish 'Check Your Health Preventive Program'. Prev Med Rep 2017:5:175-82.

55 Have Mten, Oldehinkel A, Vollebergh W, et al. Does educational background explain inequalities in care service use for mental health problems in the Dutch general population? Acta Psychiatr Scand 2003;107:178-87.

56 Korkeila J, Lehtinen V, Bijl R, et al. Establishing a set of mental health indicators for Europe. Scand J Public Health 2003;31:451-9.

57 McDaid D. Countering the stigmatisation and discrimination of people with mental health problems in Europe. European Commission, 2010.

58 Andrade LH, Alonso J, Mneimneh Z, et al. Barriers to mental health treatment: results from the who world mental health surveys. Psychol Med 2014;44:1303-17.
59 Hutton C, Gunn J. Do longer consultations improve the management of psychological problems in general practice? A systematic literature review. BMC Health Serv Res 2007;7:71.

60 Sanderson K, Andrews G. Prevalence and severity of mental health-related disability and relationship to diagnosis. Psychiatr Serv 2002;53:80.

61 Geyti C, Dalsgaard E-M, Sandbæk A, et al. Initiation and cessation of mental healthcare after mental health screening in primary care: a prospective cohort study. BMC Fam Pract 2018;19:176.

62 Richards JC, Ryan P, McCabe MP, et al. Barriers to the effective management of depression in general practice. Aust N Z J Psychiatry 2004;38:795-803.

63 Larsen FB, Friis K, Lasgaard M. Hvordan har du det? $2013-$ Sundhedsprofil for region og kommuner (Bind 1) [How are you? 2013 - Health profile for region and municipalities (vol. 1. Aarhus, 2014

64 Coghill N, Garside L, Montgomery AA, et al. Nhs health checks: a cross- sectional observational study on equity of uptake and outcomes. BMC Health Serv Res 2018;18:238.

65 Bender AM, Jørgensen T, Helbech B, et al. Socioeconomic position and participation in baseline and follow-up visits: the Inter99 study. Eur J Prev Cardiol 2014;21:899-905.

66 Hoebel J, Starker A, Jordan S, et al. Determinants of health check attendance in adults: findings from the cross-sectional German health update (GEDA) study. BMC Public Health 2014;14:913.

67 Dryden R, Williams B, McCowan C, et al. What do we know about who does and does not attend general health checks? Findings from a narrative scoping review. BMC Public Health 2012;12:723.

68 Seidler ZE, Dawes AJ, Rice SM, et al. The role of masculinity in men's help-seeking for depression: a systematic review. Clin Psychol Rev 2016;49:106-18.

69 Matcham F, Norton S, Steer S, et al. Usefulness of the SF-36 health survey in screening for depressive and anxiety disorders in rheumatoid arthritis. BMC Musculoskelet Disord 2016;17:224.

70 Wells MJ, Owen JJ, McCray LW, et al. Computer-Assisted CognitiveBehavior therapy for depression in primary care: systematic review and meta-analysis. Prim Care Companion CNS Disord 2018;20. doi:10.4088/PCC.17r02196. [Epub ahead of print: 01 Mar 2018].

71 Archer J, Bower P, Gilbody S, et al. Collaborative care for depression and anxiety problems. Cochrane Database Syst Rev 2012;10:CD006525.

72 de Lusignan S, Chan T, Parry G, et al. Referral to a new psychological therapy service is associated with reduced utilisation of healthcare and sickness absence by people with common mental health problems: a before and after comparison. J Epidemiol Community Health 2012;66:e10. 